\title{
IgE-dependent sensitization in patients with COPD
}

\author{
Andrzej Bożek ${ }^{1, B, D-F}$, Barbara Rogala',A-B,D \\ ${ }^{1}$ Clinical Department of Internal Disease, Dermatology and Allergology, Medical University of Silesia, Katowice, Poland \\ ${ }^{2}$ Clinical Department of Internal Diseases, Allergology and Clinical Immunology, Medical University of Silesia, Katowice, Poland \\ A - Research concept and design, B - Collection and/or assembly of data, C - Data analysis and interpretation, \\ $D$ - Writing the article, E - Critical revision of the article, F - Final approval of article
}

Bożek A, Rogala B. IgE-dependent sensitization in patients with COPD. Ann Agric Environ Med. 2018; 25(3): 417-420. doi: 10.26444/aaem/83413

\begin{abstract}
Introduction and objective. The aim of the study was to evaluate the differences between asthma and COPD on the basis of the prevalence and profile of IgE-dependent sensitization to inhaled allergens, and the blood serum levels of select Th1/ Th2 cytokines.

Materials and method. 103 patients with COPD (114 patients with asthma and 121 controls) were included in the study. A skin prick test with common inhaled allergens was performed, and serum levels of lgE were measured in all subjects. Lymphocyte profiles were measured via the whole-blood method using fresh $10-\mathrm{ml}$ blood samples treated with EDTA. The following surface antigens were measured: CD3, CD29, CD16, CD56, CD4, CD8, and HLA-DR. The Th1/Th2 profile in blood serum was determined using Th1/Th2 cytokine kits.

Results. IgE-dependent sensitization to environmental allergens was found in 34 (33.3\%) patients with COPD, 46 (40\%) patients with asthma and in 14 (11.5\%) volunteers. The odds ratio of sensitization in patients with COPD reached 0.89 (95\% $\mathrm{Cl}: 0.57-1.08)$ and it was more frequent than in the control population with an odds ratio of 0.71 (95\% Cl: 0.64-0.88). The serum concentration of IL-2 was significantly higher in patients with COPD and asthma than in controls. In the subgroup of patients with non-allergic asthma, similar serum concentrations were observed for all analyzed cytokines, except for IFN-gamma, which was lower in patients with COPD.

Conclusions. Both the prevalence and profile of IgE-dependent sensitization to inhaled allergens did not differ between asthma and COPD. Both Th2 and Th1 played a role in the immunopathology of asthma and COPD.

\section{Key words}

diagnostics, immunopathogenesis, biomarkers

\section{Abbreviations}

COPD-Chronic Obstructive Pulmonary Disease; FEV1 -forced expiratory volume in one second; FVC-forced expiratory volume; GINA - Global Initiative for Asthma; GOLD - Global Initiative for Chronic Obstructive Lung Disease; MMRC - Modified Medical Research Council; Th1 - lymphocyte helper 1; Th2 - lymphocyte helper 2
\end{abstract}

\section{INTRODUCTION}

Although it is well established that both asthma and COPD are immunologically driven conditions, their pathogenesis is not fully understood $[1,2,3]$. IgE-mediated sensitivity to inhaled allergens is strongly associated with asthma $[3,4]$; however, this is not true for all asthma cases. There are also a few studies that suggest sensitization to environmental allergens also in COPD patients [5, 6].

Asthma is often considered to be a Th2-driven inflammatory disease, but many cases of the disease extend beyond a simple Th2-mediated disorder [3]. Altered immune responses also determine many pathobiological processes in COPD. Moreover, pro-inflammatory cytokines promote chronic airway inflammation in both asthma and COPD $[1,7]$.

\section{OBJECTIVE}

The aim of the study was to determine whether the presence and profile of IgE-dependent sensitization and/or the serum levels of some cytokines can differ between asthma and COPD.

Address for correspondence: Andrzej Bożek, Clinical Department of Internal Disease, Dermatology and Allergology, Medical University School of Silesia, 41-800 Zabrze, M. Sklodowskiej-Curie 10, Poland

e-mail: andrzejbozek@tlen.pl

Received: 20.05.2017; accepted: 17.01.2018; first published: 22.02.2018

\section{MATERIALS AND METHOD}

There were 351 patients who dropped out of the study. Screening was performed by a family doctor, a geriatrician, an internist, an allergist, or a trained nurse in outpatient clinics. Diagnosis of asthma and COPD was based on the GINA and GOLD guidelines, respectively $[2,3]$. All patients had lung function tested by spirometry either prior to the study or during screening. Diagnosis of asthma was based on a medical history of asthma, physical examination, and partial reversal of airflow obstruction with a bronchodilator that resulted in a $12 \%$ or greater increase in $\mathrm{FEV}_{1}$ after inhalation of $400 \mathrm{mcg}$ of salbutamol. Patients with episodic asthma were excluded. Healthy volunteers were recruited from the same outpatient clinics. These groups were matched with regard to age and gender and were consistent with the demographic structure of the Polish population over the age of 60 . Additionally, 134 patients were excluded from the study because they did not fulfill the inclusion criteria. All patients signed consent forms to participate in the study which was approved by the Bioethics Committee. All of the centres obtained permission to publish the data coolected

The following patients were included in the study:

Patients with COPD. 103 participants (32 women and 71 men), age range: $41-79$, mean age: $47.9 \pm 9.1$ years. 
Inclusion criteria:

- men or women $>40$ years of age;

- a current clinical diagnosis of COPD according to the GOLD guideline with COPD symptoms lasting more than one year;

- current or previous smoker with a smoking equivalent to 10 or more pack years;

- post-bronchodilator $\mathrm{FEV}_{1}$ / forced vital capacity $(\mathrm{FVC})<0.7$ (70\%) and $30 \% \leq \mathrm{FEV} \leq 70 \%$ of predicted normal value;

- any treatment of COPD;

- a score of dyspnea $\geq 2$ according to the Modified Medical Research Council (MMRC).

Exclusion criteria:

- diagnosis of asthma or overlapping asthma/COPD syndrome;

- neoplastic disease or other unstable chronic diseases;

- any exacerbation of COPD during the six months prior to inclusion in the study (antibiotic or systemic steroids and/ or hospitalization);

- severe unstable COPD and/or oxygen therapy because of a COPD exacerbation.

B. Patients with asthma. 114 participants (42 women and 72 men), age range: $69-77$, mean $45.1 \pm 5.8$ years.

Inclusion criteria:

- men or women $>40$ years of age;

- diagnosis of asthma according to the GINA criteria with a documented history of the disease lasting at least one year;

$-60 \% \leq \mathrm{FEV}_{1} \leq 80 \%$ of predicted normal value and a positive reversibility test defined as an increase in $\mathrm{FEV}_{1} \geq 12 \%$ and $\geq 200 \mathrm{ml}$ relative to baseline after inhalation of $1 \mathrm{mg}$ terbutaline;

- any treatment of asthma.

Exclusion criteria:

- diagnosis of overlap asthma/COPD syndrome;

- neoplastic disease or other unstable diseases;

- any exacerbation of asthma during the six months prior to inclusion in the study (antibiotic and systemic steroids and/or hospitalization);

- severe, difficult to control asthma.

C. Control group. 121 participants (46 women and $75 \mathrm{men}$ ), age range: $38-81$, mean age $44.8 \pm 7.2$ years.

Inclusion criteria

- men or women $>40$ years of age.

Exclusion criteria:

- diagnosis of COPD or asthma or overlapping asthma/ COPD syndrome;

- neoplastic disease or any other unstable disease.

Characteristics of the control group, asthma patients and COPD patients are shown in Table 1.

The following procedures were performed in all patients.

Skin prick test. A skin prick test with inhaled allergens was performed according to published guidelines [8], using standardized protein extracts of $D$. pteronyssinus, $D$. farinae, grass mix, birch, alder, hazel, mugwort, Alternaria tennis,
Table 1. Characteristics of studied groups

\begin{tabular}{lcccc}
\hline & $\begin{array}{c}\text { COPD } \\
\mathrm{N}=103\end{array}$ & $\begin{array}{c}\text { Asthma } \\
\mathrm{N}=114\end{array}$ & $\begin{array}{c}\text { Control subjects } \\
\mathrm{N}=121\end{array}$ & $\mathrm{P}$ \\
\hline Smokers & $92^{*}$ & 46 & 45 & 0.003 \\
\hline Non-urban residents & 19 & 22 & 14 & $\mathrm{NS}$ \\
\hline Time of disease duration ( $\pm \mathrm{SD})$ & $11.8 \pm 6.2$ & $9.1 \pm 5.2$ & - & $\mathrm{NS}$ \\
\hline Coronary disease & 65 & $32^{*}$ & 54 & 0.02 \\
\hline Arterial hypertension & 56 & 62 & 53 & $\mathrm{NS}$ \\
\hline Diabetes mellitus & 31 & $11^{*}$ & 25 & 0.03 \\
\hline Positive family history of asthma & 11 & $35^{*}$ & 12 & 0.04 \\
\hline Positive family history of COPD & $45^{*}$ & 15 & 13 & 0.01 \\
\hline Disease duration (in years) & $5.3 \pm 2.1^{*}$ & $3.9 \pm 2.1$ & - & 0.02 \\
\hline *Multivariate AnOvA test; NS - not statistically significant & & &
\end{tabular}

Cladosporium herbarium, Aspergillus fumigatus, cat, dog and cockroach (Allergopharma diagnostic set, Allergopharma, Reinbeck, Germany). A positive result was defined as a wheal $>3 \mathrm{~mm}$ in diameter, $20 \mathrm{~min}$. after allergen extract application.

Serum levels of allergen-specific IgE. (sIgE) against the above-mentioned allergens were measured by ImmunoCAP (Pharmacia AB, Sweden), according to the manufacturer's instructions. sIgE levels greater than $0.35 \mathrm{kUA} / \mathrm{l}$ were considered to be positive.

Immune analyses. Lymphocyte profiles were measured by the whole-blood method using fresh $10 \mathrm{ml}$ blood samples that were treated with EDTA. The following lymphocyte markers were measured using ImmunoGEN kits (BD Bioscience, US) and a FACS Canto II flow cytometer (Becton Dickinson, US): CD3, CD29, CD16, CD56, CD4, CD8, and HLA-DR. To identify the Th1/Th2 profile, IL-2, IL-4, IL-5, IL-10, TNF, and IFN-gamma concentrations in the blood were measured using the human Th1/Th2 cytokine kit II (ImmunoGEN, US) and a flow cytometer, as previously described. Cytokine concentrations are presented in $\mathrm{pg} / \mathrm{ml}$. Assay sensitivity for each cytokine were as follows: for Il-2, $>31.2 \mathrm{pg} / \mathrm{ml}$; Il-4, $10 \mathrm{pg} / \mathrm{ml}$; Il-5, >5.1 pg/ml; Il-10, >11.6 pg/ml; Il-13, >13.6 $\mathrm{pg} / \mathrm{ml}$; TNF $>6.5 \mathrm{pg} / \mathrm{ml}$; and IFN-gamma, $>5.2 \mathrm{pg} / \mathrm{ml}$.

Statistical analyses. Non-parametric statistical analyses were performed using the chi-square test and the multivariate ANOVA test. The risk of allergy symptoms was presented as a Hazard ratio. Spearman's rank correlation test was used to examine any possible trends. The median and interquartile range were calculated for each cytokine. Statistica programme, version 8.0 (StatSoft, Poland) was used for all statistical analyses. A P value $<0.05$ was considered to be statistically significant, following Bonferroni's correction.

\section{RESULTS}

IgE-dependent sensitization was observed in 34 (33.3\%) patients with a diagnosis of COPD. This was higher than the incidence of sensitization in the healthy subjects group (14 patients, $11.5 \%$ ) but lower than that observed in asthma patients (46 patients, 40\%). The sensitization profile for asthma patients was similar to that observed for COPD patients (Tab. 2). 32 patients with COPD were diagnosed with allergic rhinitis (sporadic in 14 patients and chronic 
Table 2. Comparison of the skin test results in the studied groups

\begin{tabular}{lcccc}
\hline \multirow{2}{*}{ Allergens } & $\begin{array}{c}\text { COPD } \\
\mathrm{N}=103\end{array}$ & $\begin{array}{c}\text { Asthma** } \\
\mathrm{N}=114\end{array}$ & $\begin{array}{c}\text { Control group } \\
\mathrm{N}=121\end{array}$ & $\mathrm{P}$ \\
\cline { 2 - 5 } D. pteronyssinus & 29 & 62 & 9 & 0.01 \\
\cline { 1 - 4 } D. farinae & 23 & 59 & 8 & 0.01 \\
\hline Grass & 16 & 48 & 7 & 0.01 \\
\hline Birch & 6 & 19 & 6 & 0.01 \\
\hline Alder & 8 & 18 & 4 & 0.03 \\
\hline Hazel & 7 & 23 & 3 & 0.004 \\
\hline Mugwort & 14 & 35 & 7 & 0.04 \\
\hline Alternaria & 13 & 25 & 4 & 0.01 \\
\hline Cladosporium & 8 & 31 & 2 & 0.009 \\
\hline Aspergillus & 4 & 9 & 5 & $\mathrm{NS}$ \\
\hline Cat & 6 & 15 & 8 & 0.03 \\
\hline Dog & 2 & 3 & 0 & $\mathrm{NS}$ \\
\hline Cockroach & 11 & 14 & 9 & $\mathrm{NS}$ \\
\hline Multivariate ANOVA test; ** all positive results were in patients with allergic asthma; NS - not \\
statistically significant
\end{tabular}

in 18 patients), and a diagnosis of atopic dermatitis was confirmed in 7 subjects.

The odds ratio of IgE-dependent sensitization in patients with COPD reached 0.89 (95\% CI: $0.57-1.08)$. This was higher than the ratio of 0.71 ( $95 \%$ CI: $0.64-0.88)$ for the healthy population, and lower than the ratio of 1.24 (95\% CI: 0.831.44) for the asthma patients.

The serum level of total IgE was comparable for COPD, asthma patients, and healthy volunteers $(59.7 \pm 11.8 \mathrm{IU} / \mathrm{L}$, $70,5+32,8 \mathrm{IU} / \mathrm{L}$, and $62.1 \pm 22.5 \mathrm{IU} / \mathrm{L}$, respectively). However, in patients with allergic asthma, the mean concentration of total IgE was $148.1 \pm 98.4 \mathrm{IU} / \mathrm{L}$, which was significantly higher than in the other groups $(p<0.05)$.

The serum concentrations of sIgE against $D$. pteronyssinus and $D$. farinae were predominantly higher in patients with asthma than in the other groups. Similar results were obtained with regard to concentrations of sIgE against Alternaria, grass, birch, hazel and alder pollens. The concentrations of sIgE against other allergens were comparable in all the groups analyzed.

Th1/Th2 profile. The serum concentration of IL-2 was significantly higher in both COPD and asthma patients than in healthy subjects (Tab. 3). When the subgroup of patients with non-allergic asthma was compared with patients with $\mathrm{COPD}$, they were found to have similar serum concentrations

Table 3. Th1/Th2 profiles in the studied groups

\begin{tabular}{lcccc}
\hline Cytokine & COPD & Asthma & Control group & \\
\cline { 1 - 4 } & $\mathrm{N}=103$ & $\mathrm{~N}=114$ & $\mathrm{~N}=121$ & $\mathrm{P}$ \\
\cline { 1 - 4 } Median with interquartile range $(\mathrm{pg} / \mathrm{ml})$ & \\
\hline IL-2 & $11.9 ; 10.6-12.11$ & $13.19 ; 4.33-7.12$ & $3.94 ; 1.21-4.10^{*}$ & 0,0001 \\
\hline IL-4 & $5.12 ; 4.45-5.99$ & $6.22 ; 5.22-7.12$ & $1.89 ; 1.19-2.71^{*}$ & 0,007 \\
\hline IL-5 & $3.25 ; 2.02-4.11$ & $3.51 ; 2.21-4.14$ & $2.91 ; 2.11-3.41$ & NS \\
\hline IL-10 & $21.81 ; 18.33-12.61$ & $23.01 ; 22.11-24.81$ & $10.38 ; 9.44-12.82^{*}$ & 0,014 \\
\hline TNF & $14.09 ; 13.76-15.32$ & $16.1 ; 15.09-17.03$ & $9.12 ; 8.56-10.01^{*}$ & 0,022 \\
\hline IFN-gamma & $7.74 ; 6.55-8.12$ & $6.14 ; 5.42-7.31$ & $3.45 ; 2.27-4.07^{*}$ & 0,014 \\
\hline
\end{tabular}

"Multivariate ANOVA test; NS - not statistically significant
Table 4. Th1/Th2 profile in patients with COPD and non-allergic asthma

\begin{tabular}{lccc}
\hline Cytokine & $\begin{array}{c}\text { COPD } \\
\mathrm{N}=103\end{array}$ & $\begin{array}{c}\text { Non-atopic asthma } \\
\mathrm{N}=41\end{array}$ & $\mathrm{P}$ \\
\cline { 1 - 3 } & \multicolumn{2}{c}{ Median with interquartile range $(\mathrm{pg} / \mathrm{ml})$} & \\
\hline IL-2 & $11.9 ; 10.6-12.11$ & $9.17 ; 8.22-11.104$ & NS \\
\hline IL-4 & $5.12 ; 4.45-5.99$ & $4.01 ; 3.21-4.68$ & NS \\
\hline IL-5 & $3.25 ; 2.02-4.11$ & $3.11 ; 2.91-4.02$ & NS \\
\hline IL-10 & $21.81 ; 18.33-12.61$ & $22.01 ; 19.04-23.15$ & NS \\
\hline TNF & $14.09 ; 13.76-15.32$ & $17.04 ; 16.48-17.87$ & NS \\
\hline IFN-gamma & $7.74 ; 6.55-8.12$ & $10.11 ; 9.11-11.31^{*}$ & 0.02 \\
\hline
\end{tabular}

"Multivariate ANOVA test; NS - not statistically significant

of all cytokines, except for IFN gamma, which was lower in patients with COPD (Tab. 4).

\section{DISCUSSION}

Both asthma and COPD are immunologically-driven disorders that are influenced by complex epigenetic agents [1, $9,10]$. It is commonly accepted that asthma is predominantly a Th2 cell-mediated inflammatory disease [3, 10], while COPD is associated with Th1 activity $[1,2]$. IgE-mediated sensitivity to common aeroallergens is strongly associated with asthma pathogenesis [3]; however, the role of IgE-mediated sensitivity in COPD is less clear $[11,12]$.

In the presented study, atopy was associated with asthma, as expected, although atopic characteristics were also noted in COPD patients. Also as expected, sensitization to mites was observed in most asthmatics [3]. Hypersensitivity to Alternaria was also frequently observed in this group of patients. Nevertheless, sensitization to these allergens was also detected in those suffering from COPD, and significantly more frequently than in patients with non-allergic asthma or in the control group. These observations are in concordance with common knowledge about the role of airborne allergens in the pathophysiology of asthma, but airborne allergens are rarely believed to be associated with COPD $[13,14]$. The similar sensitization profiles in patients with asthma and COPD observed in this study support the concept that asthma and COPD share some immunological features. The findings of the current study are in partial agreement with the results of Simpson et al. who demonstrated that Th1- and Th2-mediated disorders are positively correlated [15]. Moreover, these observations suggest a common origin for both commonly prevalent bronchoconstriction diseases.

The authors wish to emphasize that exposure to a variety of environmental factors plays a role in the development of these two immune diseases. The nature of these environmental factors, including allergens, smoking, and air pollution, determines whether asthma or COPD develops. Holt et al. suggest that allergic asthma, non-allergic asthma, and COPD are offshoots of a common 'at-risk' pathway underpinned by genotypes related to aberrations in control of host defence and tissue repair mechanisms [16]. They proposed that initiation of this pathway is programmed by the environmental experience of the immune system during infancy and early childhood, in particular by respiratory tract infections or sensitization to inhaled allergens in 'atrisk' subjects. The similar patterns in Th1/Th2 cytokines detected in patients with asthma and COPD in the presented 
study support this notion. It is worth noting that both the asthma and COPD patients included in this study suffered from a moderate and stable form of the disease, with no exacerbations during the 12 months prior to inclusion in the study. However, in comparison wit COPD patients, the asthma patients had more frequent family histories of allergy and a longer duration of the disease [16].

Both Th 2 cells and Th1 cells express a panel of cytokines. IL-4, IL-3, IL-10, IL-13 and GM-CSF are released by Th2 cells. Th1 cells are recognized by the expression and release of IL-2, IFN-gamma, and TNF-alpha $[17,18]$. We evaluated a number of cytokines in our study to determine whether the polarization of the Th1/Th2 response at the serum level could differentiate asthma and COPD based on these data. The serum concentrations of all the cytokines evaluated in both asthma and COPD were similar, except at the lower level of IFN-gamma in COPD. This is important because the IFN-gamma plays a critical role in the innate and adaptive immune responses to viral and bacterial infections. IFNgamma is predominantly produced by natural killer cells and by Th1 cells upon antigen-specific immune stimulation. There are data indicating that that low IFN-gamma levels in serum suppress anti-tumour immunity [19]. IL-2 is a potent pro-inflammatory cytokine primarily released by Th0 and Th1 cells upon activation. IL-2 is commonly accepted to play a crucial role in the induction and maintenance of inflammatory processes in the airways [20,21].

IL-4 has a dominant role in driving the differentiation of CD4+Th precursors into Th2 cells. It determines IgE synthesis by B lymphocytes and increases the expression of the low-affinity receptor for IgE (FceRII/CD23) to enhance antigen presentation by $\mathrm{B}$ cells. Moreover, inhalation of recombinant IL- 4 has been shown to induce airway hyperresponsiveness and sputum eosinophils, providing evidence for the important role that this cytokine plays in the pathophysiology of asthma [22].

The similar cytokine profiles in asthma and COPD provide indirect evidence for the involvement of both Th1 and Th2 cells in the pathophysiology of these two disorders. IgEdependent sensitization to airborne allergens has also been observed with comparable frequencies in asthma and COPD patients. It is worth noting that this was only the case for allergic asthma. In the presented study, more predominant atopy characteristics were observed in COPD than nonallergic asthma.

The results obtained reflect only a part of the complex network of immunologically- driven inflammatory processes in the airways of patients with bronchoconstriction diseases.

The inability of this study to differentiate between asthma and COPD patients based on their serum cytokine levels, indicates that neither Th2 nor Th1 related cytokines can be used as biomarkers for these disorders. Over-activation of either Th1 or Th2 responses occurs in both the pathogenesis of asthma and COPD. IgE-mediated sensitization plays a role not only in the pathogenesis of allergic asthma but also in the pathophysiology of COPD.

\section{CONCLUSIONS}

Neither IgE-dependent sensitization profiles to inhaled allergens, nor the profiles of Th1 and Th2 cytokine measured in patient serum, could differentiate between asthma and COPD patients with stable disease. The data obtained suggest that the pathophysiology of bronchoconstriction in asthma and COPD share some common features.

\section{REFERENCES}

1. Barnes PJ. Therapeutic approaches to asthma-chronic obstructive pulmonary disease overlap syndromes. J Allergy Clin Immunol. 2015; 136: 531-45.

2. Global Initiative for Chronic Obstructive Lung Disease (GOLD) Updated 2015. http//: www.goldcopd.it/materiale/2015/GOLD_ Report_2015.pdf (accessed 20.01.16)

3. Global Initiative for Asthma GINA. http//: www.gina.org/2015 (accessed 22.03.15)

4. Mathur SK, Viswanathan RK. Relevance of allergy in adult asthma. Curr Allergy Asthma Rep. 2014; 14: 437.

5. Neves MC, Neves YC, Mendes CM, Bastos MN, Camelier AA, Queiroz CF, Mendoza BF, Lemos AC, D'Oliveira Junior A. Evaluation of atopy in patients with COPD. J Bras Pneumol. 2013; 39: 296-305.

6. Fattahi F, ten Hacken NH, Löfdahl CG, Hylkema MN, Timens W, Postma DS,Vonk JM. Atopy is a risk factor for respiratory symptoms in COPD patients: results from the EUROSCOP study. Respir Res. 2013; 28 (14):10.

7. Braman SS. The chronic obstructive pulmonary disease-asthma overlap syndrome. Allergy Asthma Proc. 2015; 36: 11-8.

8. Heinzerling LM, Burbach GJ, Edenharter G, Bachert C, Bindslev-Jensen C, Bonini S, et al. GA(2)LEN skin test study I: GA(2)LEN harmonization of skin prick testing: novel sensitization patterns for inhalant allergens in Europe. Allergy. 2009; 64: 1498-1506.

9. Hizawa N. Clinical approaches towards asthma and chronic obstructive pulmonary disease based on the heterogeneity of disease pathogenesis. Clin Exp Allergy. 2016; 46: 678-87.

10. Ichinose M. Differences of inflammatory mechanisms in asthma and COPD. Allergol Int. 2009; 58: 307-13.

11. Li BW, Hendriks RW. Group 2 innate lymphoid cells in lung inflammation. Immunology. 2013; 140: 281-287.

12. Tsai JJ, Liao EC, Hsu JY, Lee WJ, Lai YK. The differences of eosinophiland neutrophil-related inflammation in elderly allergic and non-allergic chronic obstructive pulmonary disease. J Asthma. 2010; 47: 1040-4.

13. Ogershok PR, Warner DJ, Hogan MB, Wilson NW. Prevalence of pollen sensitization in younger children who have asthma. Allergy Asthma Proc. 2007; 28: 654-658.

14. Pawankar R, Canonica GW, Holgate ST, Lockey RF. Allergic diseases and asthma: a major global health concern. Curr Opin Allergy Clin Immunol. 2012; 12: 39-41.

15. Simpson CR, Anderson WJ, Helms PJ, Taylor MW, Watson L, Prescott GJ, Godden DJ, Barker RN. Coincidence of immune-mediated diseases driven by Th1 and Th2 subsets suggests a common aetiology. A population-based study using computerized general practice data. Clin Exp Allergy. 2002; 32: 37-42.

16. Holt PG, Sly PD. Non-atopic intrinsic asthma and the 'family tree' of chronic respiratory disease syndromes. Clin Exp Allergy. 2009; 39: 807-11.

17. Ngoc PL, Gold DR, Tzianabos AO, Weiss ST, Celedón JC. Cytokines, allergy, and asthma. Curr Opin Allergy Clin Immunol. 2005; 5; 161-166.

18. Shirai T, Inui N, Suda T, Chida K. Correlation between peripheral blood T-cell profiles and airway inflammation in atopic asthma. J Allergy Clin Immunol. 2006; 118: 622-6.

19. Schoenborn JR, Wilson CB. Regulation of interferon-gamma during innate and adaptive immune responses. Adv Immunol. 2007; 96: 41-101.

20. Liao W, Lin JX, Leonard WJ. IL-2 family cytokines: new insights into the complex roles of IL-2 as a broad regulator of Thelper cell differentiation. Curr Opin Immunol. 2011; 23: 598-604.

21. Malek TR, Castro I. Interleukin-2 receptor signaling: at the interface between tolerance and immunity. Immunity 2010; 27:153-65.

22. Perkins PC, Wills-Karp M, Finkelman FD. IL-4 induces IL-13independent allergic airway inflammation. J Allergy Clin Immunol 2006; 118: 410-9. 